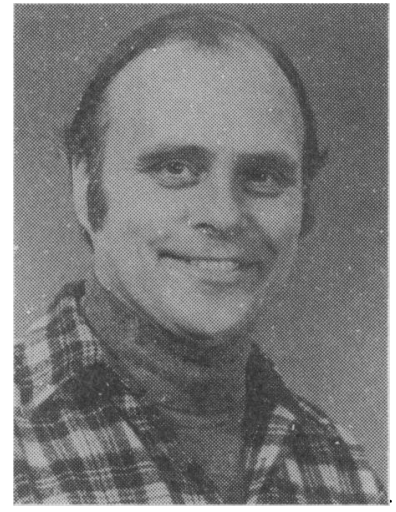

P. J. Maud

\section{PHYSIOLOGICAL AND ANTHROPOMETRIC PARAMETERS THAT DESCRIBE A RUGBY UNION TEAM}

\author{
P. J. MAUD, DipPE, PhD
}

Department of Physical Education, State University of New York College at Brockport, Brockport, New York 14420, USA

The purpose of this study was to describe the anthropometric and physiological parameters that apply to a USA amateur rugby union club team. Fifteen players who were members of the club's first team were evaluated for body composition, muscular strength, power and endurance, flexibility, anaerobic power, anaerobic capacity, and cardiorespiratory function shortly after completion of the regular season. Means for some of the variables measured include: age, $29 \mathrm{yr}$; height, $180 \mathrm{~cm}$; weight, $84 \mathrm{~kg}$; lean body weight, $74 \mathrm{~kg}$; body fat, 12\%, endurance sit-ups, $50 / \mathrm{min}$; vertical jump height, $51 \mathrm{~cm}$; anaerobic power output, $132 \mathrm{~m} . \mathrm{kg} . \mathrm{s}^{-1}$ (1.32 kw); anaerobic capacity, $2247 \mathrm{~m} . \mathrm{kp} / 40 \mathrm{~s}(22.5 \mathrm{~kJ})$; maximum heart rate, 186 beats $/ \mathrm{min}$ maximum ventilation, $175 \mathrm{I} / \mathrm{min}^{-1}$; maximum respiratory quotient 1.23; and maximum oxygen uptake, $56.6 \mathrm{ml}^{\mathrm{kg}} \mathrm{kgin}^{-1} \mathrm{~m}^{-1}$.

In comparison with other rugby players studied these players had higher maximum oxygen uptake values, were similar in endurance sit-up and vertical jump ability, exhibited less upper body strength, and the forwards had lower body fat percentages. They were generally within the range of scores found to describe the aerobic and anaerobic fitness, and body composition of other élite amateur and professional intermittent sport athletes.

\section{INTRODUCTION}

Numerous studies, as reported by Wilmore (1979), have been undertaken in recent years to document the physiological and anthropometric profiles of competitors in a wide variety of sports. However, despite the world-wide popularity of rugby union as a team sport, there is limited data available that illustrates both the physiological and anthropometric characteristics of players of a rugby union team. Some studies, such as those undertaken by Bell (1973, 1979, 1980), have reported quite extensively on body composition, and some, as for example those by Bell (1980), Williams et al (1973), and Reid and Williams (1974), have included the results of physiological tests of aerobic capacity. Field fitness test results have been documented for such factors as muscular strength, power and endurance, agility, speed, and both aerobic and anaerobic capacity by Evans $(1969,1973)$ and Howe (1980, 1981). Hatakeyama et al (1976) have reported some body composition, speed, muscular power, and muscular strength measures for players over $\mathbf{4 0}$ years of age.

This study attempts to provide a relatively comprehensive profile of the physiological and anthropometric parameters that describe one particular rugby union club team in USA and to provide a basis for further studies designed to assess those qualities needed for successful participation in the sport. For comparison purposes, individual scores are included as are the means for both the total team and the two sub-groups consisting of forward and backline players.

\section{METHODS}

The 15 subjects that comprised the study were all members of the Rochester Aardvarks Rugby Club First XV during the 1981 Fall season. The club had been relatively successful, winning six, losing three, and drawing one game, in competition against both city and college club sides. All players practiced twice and played once per week during the season and trained independently on average two additional times per week. Playing experience averaged 7.7 years and ranged from one to 19 years, and eight of the players were either current or past members of the Upstate New York Rugby Union's representative team.

Each player was scheduled for two days of testing, approximately seven days apart, shortly after comple- 
tion of their last game of the season. During the first test session muscular strength, body height and weight, muscular power, flexibility, and aerobic capacity were measured in the order listed. On the second day subjects were tested for muscular endurance and anaerobic capacity.

Body weight was recorded to the nearest $0.01 \mathrm{~kg}$ and height to the nearest $0.5 \mathrm{~cm}$. Skinfold measurements were taken on the right side of the body at the thigh, abdomen, and chest using a Lange skinfold caliper having a constant pressure of $10 \mathrm{~g} \cdot \mathrm{mm}^{-2}$. Body density was determined by use of the equations developed by Jackson and Pollock (1978) with the formula of Brozek et al (1963) used to derive percent fat from body density.

Muscular strength, using typical Universal Gym equipment ${ }^{*}$, was determined by the one repetition maximum (1RM) method following a warm-up using light weights. Bench press was determined to the nearest 10 lbs with bench height adjusted so that the bar was in

*Universal Gym Co., Hempstead, Long Island, NY 11550. line with the manubrium at the commencement of the press. Starting position for the leg press was with the knees flexed to $90^{\circ}$ and the feet placed on the upper of the two sets of foot rests, and maximum strength recorded to the nearest $\mathbf{3 0}$ lbs. Measurements were converted from lbs to $\mathrm{kg}$ for standardisation purposes.

The sit and reach test to determine flexibility of the lower back and posterior thigh muscles was administered according to the procedure described by Wilmore (1977) with measurements subsequently converted from ins to cms. Muscular power was measured by vertical jump using a typical protocol as described by Annarino (1976), and endurance of the abdominal muscles by a 60-second bent leg sit-up test as described in The Y's Way to Physical Fitness by Myers et al, 1973.

Anaerobic power was derived from body weight and the results of the vertical jump power test using the Lewis equation as described by Fox and Mathews (1974) with scores recorded in m.kg. ${ }^{-1}$. The anaerobic capacity test utilised the protocol of Katch et al (1977) where subjects completed an all-out pedalling task on a mechanically braked Monark ergometer against a frictional resistance of $6 \mathrm{kp}$ for a duration of $\mathbf{4 0}$ seconds. Total

\section{TABLE I}

Anthropometric description of a rugby union team.

\begin{tabular}{|c|c|c|c|c|c|}
\hline Position & $\begin{array}{l}\text { Age } \\
\text { (yr) }\end{array}$ & $\begin{array}{l}\text { Height } \\
(\mathrm{cm})\end{array}$ & $\begin{array}{l}\text { Weight } \\
\text { (kg) }\end{array}$ & $\begin{array}{l}\text { Body Fat } \\
(\%)\end{array}$ & $\begin{array}{l}\text { Lean Body Weigh } \\
(\mathrm{kg})\end{array}$ \\
\hline \multicolumn{6}{|l|}{ Forwards } \\
\hline Prop & 34 & 181 & 88.8 & 15.7 & 74.8 \\
\hline Prop & 24 & 184 & 95.5 & 11.2 & 84.7 \\
\hline Hooker & 25 & 160 & 69.9 & 6.5 & 65.4 \\
\hline Lock & 28 & 185 & 93.0 & 14.2 & 79.8 \\
\hline Flanker & 29 & 184 & 88.8 & 16.2 & 74.4 \\
\hline No. 8 & 38 & 185 & 91.0 & 15.5 & 76.9 \\
\hline $\begin{array}{l}\text { Forwards Mean } \pm \text { S.D. } \\
( \pm \text { S.E.) }\end{array}$ & $\begin{array}{c}30.7 \pm 5.1 \\
\quad(1.8)\end{array}$ & $\begin{array}{c}180.7 \pm 8.7 \\
(3.1)\end{array}$ & $\begin{array}{c}87.7 \pm 7.7 \\
(2.7)\end{array}$ & $\begin{array}{l}12.4 \pm 3.5 \\
\quad(1.2)\end{array}$ & $\begin{array}{c}76.7 \pm 5.6 \\
(2.0)\end{array}$ \\
\hline \multicolumn{6}{|l|}{ Backs } \\
\hline Wing & 23 & 178 & 74.6 & 7.5 & 69.0 \\
\hline Wing & 23 & 184 & 85.9 & 12.1 & 75.6 \\
\hline Full Back & 25 & 169 & 79.0 & 15.5 & 66.7 \\
\hline $\begin{array}{l}\text { Backs Mean } \pm \text { S.D. } \\
( \pm \text { S.E.) }\end{array}$ & $\begin{array}{c}26.0 \pm 3.7 \\
(1.4)\end{array}$ & $\begin{array}{c}178.4 \pm 7.3 \\
(2.7)\end{array}$ & $\begin{array}{c}80.5 \pm 6.1 \\
(2.3)\end{array}$ & $\begin{array}{l}11.7 \pm 4.9 \\
(1.9)\end{array}$ & $\begin{array}{c}71.0 \pm 4.7 \\
(1.8)\end{array}$ \\
\hline $\begin{array}{l}\text { Total Team Mean } \pm \text { S.D. } \\
( \pm \text { S.E. })\end{array}$ & $\begin{array}{l}28.5 \pm 5.0 \\
\quad(1.3)\end{array}$ & $\begin{array}{c}179.7 \pm 7.9 \\
(2.0)\end{array}$ & $\begin{array}{c}84.4 \pm 7.7 \\
(2.0)\end{array}$ & $\begin{array}{l}12.0 \pm 4.1 \\
(1.1)\end{array}$ & $\begin{array}{l}74.0 \pm 5.9 \\
(1.5)\end{array}$ \\
\hline
\end{tabular}


TABLE II

Flexibility, muscular strength, endurance, and power scores of a rugby union team.

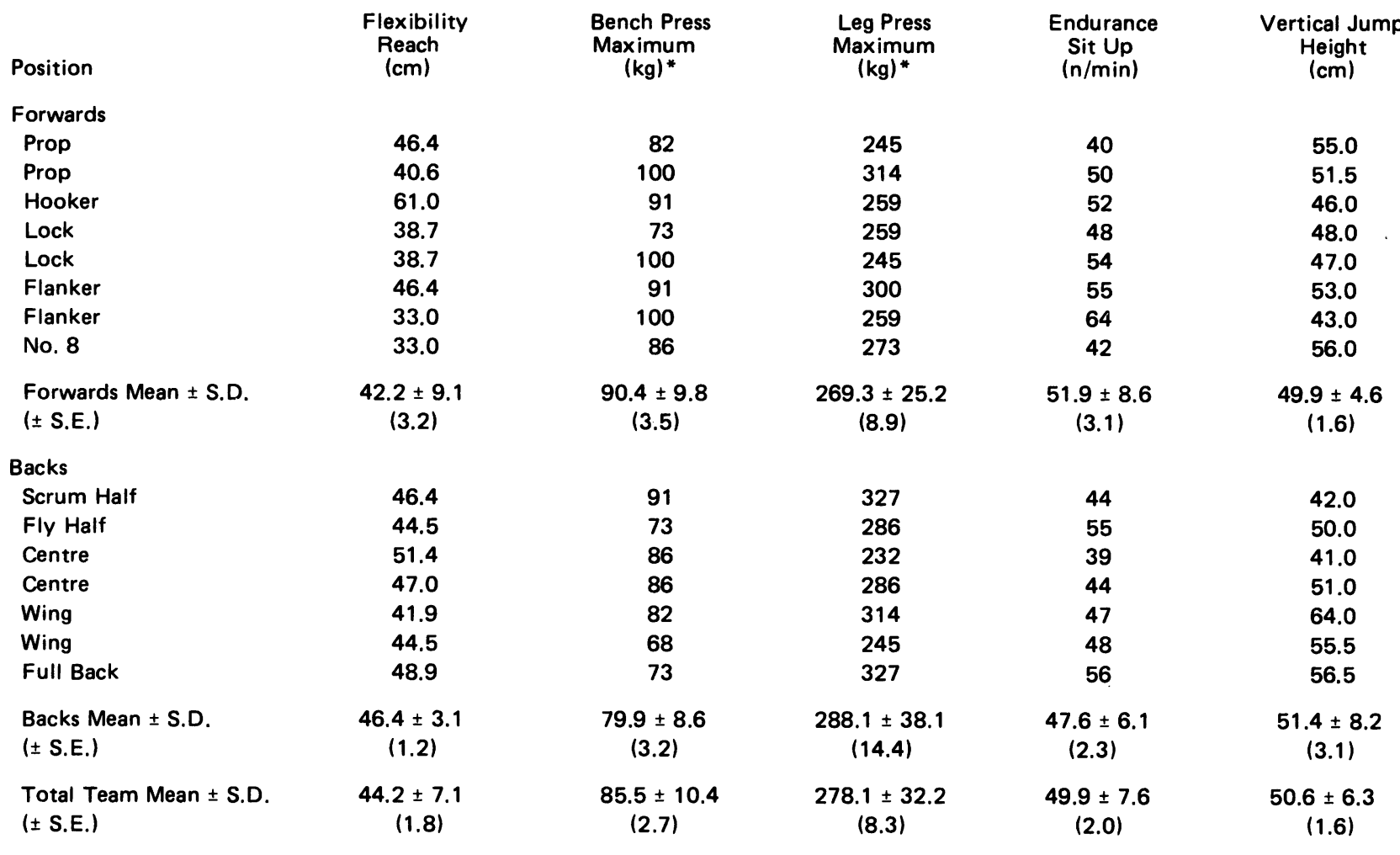

* Strength measurements were obtained in Ibs using a typical Universal Gym apparatus with leg press recorded to the nearest 30 lbs and bench press to the nearest $10 \mathrm{lbs}$. The $\mathrm{lb}$ measurement was then converted to $\mathrm{kg}$.

pedal revolutions to the nearest one-half revolution were recorded and work completed reported in m.kp/40 sec.

Aerobic capacity, as defined by maximum oxygen uptake, was determined using a standard Bruce treadmill protocol (McDonough et al, 1970). The test was terminated when the subject, due to fatigue, was no longer able to continue. During the test, ECG was monitored using a modified $V_{5}$ lead and heart rates obtained during the last ten seconds of each minute of the test. A 45-second sample of expired air was collected in neoprene meteorological balloons during each of the final two or three minutes of the test and analysed for $V_{E}$, $\mathrm{F}_{\mathrm{E}} \mathrm{CO}_{2}$, and $\mathrm{F}_{\mathrm{E}} \mathrm{O}_{2}$. Component equipment included a mouth valve, gas meter and $\mathrm{O}_{2}$ and $\mathrm{CO}_{2}$ gas analysers. The metabolic techniques and procedures described by Consolazio et al (1963) were followed.

Means, standard deviations, and standard error of the mean were calculated for the total team and for the two sub-groups consisting of forward and backline players. One way analysis of variance was used to determine whether any significant differences existed between forward and backline players.

\section{RESULTS}

The physical characteristics of the players are presented in Table I while Table II gives results of the field tests of flexibility, muscular strength, power and endurance. Table III reports the results of the anaerobic power and capacity tests, and Table IV the $\mathrm{VO}_{2}$ max values and associated metabolic data including $H R$ max, VE max and $R$ max.

In comparing the differences between the forward and backline players, univariate analysis revealed only four variables that had probability levels less than the 0.1 level. Due to the fact that a total of 16 variables had been analysed, none of these were deemed to be statistically significant. Probability levels for the four variables less than the 0.1 level were bench press $<0.05$, 
TABLE IV

Aerobic capacity of a rugby union team.

\begin{tabular}{|c|c|c|}
\hline Position & 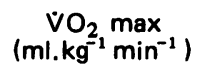 & $\begin{array}{l}\mathrm{VO}_{2} \max \\
\left(1 . \min ^{-1}\right)\end{array}$ \\
\hline \multicolumn{3}{|l|}{ Forwards } \\
\hline Prop & 49.9 & 4.42 \\
\hline Prop & 51.0 & 4.86 \\
\hline Hooker & 56.2 & 3.92 \\
\hline Lock & 52.8 & 4.89 \\
\hline Lock & 61.5 & 5.38 \\
\hline Flanker & 53.4 & 4.67 \\
\hline Flanker & 61.1 & 5.42 \\
\hline No. 8 & 46.8 & 4.25 \\
\hline $\begin{array}{l}\text { Forwards Mean } \pm \text { S.D. } \\
( \pm \text { S.E. })\end{array}$ & $\begin{array}{l}54.1 \pm 5.2 \\
\quad(1.8)\end{array}$ & $\begin{array}{c}4.73 \pm 0.51 \\
(0.19)\end{array}$ \\
\hline \multicolumn{3}{|l|}{ Backs } \\
\hline Scrum Half & 57.8 & 4.50 \\
\hline Fly Half & 57.4 & 4.22 \\
\hline Centre & 64.3 & 5.25 \\
\hline Centre & 57.9 & 5.23 \\
\hline Wing & 71.3 & 5.31 \\
\hline Wing & 51.6 & 4.42 \\
\hline Full Back & 56.2 & 4.43 \\
\hline $\begin{array}{l}\text { Backs Mean } \pm \text { S.D. } \\
( \pm \text { S.E. })\end{array}$ & $\begin{array}{l}59.5 \pm 6.4 \\
(2.4)\end{array}$ & $\begin{array}{c}4.77 \pm 0.47 \\
(0.18)\end{array}$ \\
\hline $\begin{array}{l}\text { Total Team Mean } \pm \text { S.D. } \\
\text { ( } \pm \text { S.E. })\end{array}$ & $\begin{array}{l}56.6 \pm 6.2 \\
\quad(1.6)\end{array}$ & $\begin{array}{c}4.75 \pm 0.48 \\
(0.13)\end{array}$ \\
\hline
\end{tabular}

age $<0.06$, weight $<0.07$, and $\mathrm{VO}_{2} \max <0.09$.

Although not statistically significant, descriptive analysis indicated that forwards in comparison with backs were older, heavier, slightly taller, and were marginally higher in percentage body fat. In other tests the forwards scored higher in the endurance sit-up test, anaerobic power output, anaerobic capacity, and in the bench press, while they scored lower in flexibility, in leg press, in vertical jump, and in all metabolic measurements.

\section{DISCUSSION}

A comparison of anthropometric and $\mathrm{VO}_{2} \max$ data between the current study and other rugby and selected intermittent sport studies is shown in Table V.

The mean body fat percentages of the combined forward and backline players was $12.0 \%$ and was similar to those players, mean $12.7 \%$, studied by Williams et al (1973). In comparison to Bell's data $(1979,1980)$ the backline players had similar body fat percentages but the forwards of the Rochester team were leaner, $12.4 \%$ compared to $19.5 \%$ and $14.2 \%$ body fat.

$\begin{array}{r}H R \max \\ \text { (beats/min }\end{array}$
175
169
194
190
176
188
186
181
$182.4 \pm 8.6$
$(3.0)$

193
185
178
183
191
200
195
$189.3 \pm 7.6$
$(2.9)$
$185.6 \pm 8.6$
$(2.2)$

(2.2)

Professional soccer players described by Raven et al (1976), professional basketball players (Parr et al, 1978), Olympic wrestlers (Silva et al, 1982), and college ice hockey players all had lower body fat percentages than the Rochester rugby players who were, however,

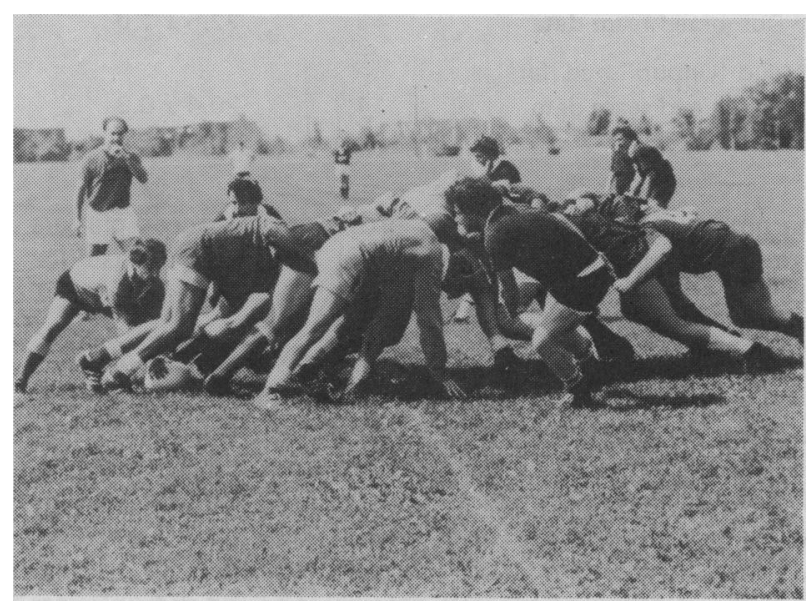

Rochester Aardvarks (left) v. S.U.N.Y. Brockport (right) 


\section{TABLE V}

A comparison of selected data between the current study and other rugby and intermittent sport studies (*Data is reported \pm the standard error of the mean)

\section{Subjects}

Combined team data

Other rugby studies

$$
\begin{aligned}
& \text { Bell (1979) } \\
& \text { Forwards } \\
& \text { Backs } \\
& \text { Bell (1980) } \\
& \text { Forwards } \\
& \text { Williams et al (1973) } \\
& \text { Combined team data } \\
& \text { Reid and Williams (197 } \\
& \text { Combined team dat } \\
& \text { Soccer Studies } \\
& \text { Raven et al (1978) } \\
& \text { Combined team data } \\
& \text { Williams et al (1976) } \\
& \text { Wrestling Studies } \\
& \text { Silva et al (1982) } \\
& \text { Olympic qualifiers } \\
& \text { (VO }{ }_{2} \text { max } n=23 \text { ) } \\
& \text { Basketball Studies } \\
& \text { Parr et al (1978) } \\
& \text { Forwards } \\
& \text { Guards }
\end{aligned}
$$

Combined team data

Reid and Williams (1974)

Combined team data

Combined team data

Ice Hockey Studies

Rusko et al (1978)

Combined team data

Maud (Unpublished data)

Combined team data

$25.6 \pm 1.0$

\section{5}

15

$25.3 \pm 1.0$

$24.2 \pm 0.9$

$22.5 \pm 1.0$

14

$20.4 \pm 0.3$ (n)

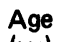

(yr)

$$
\begin{aligned}
& 30.7 \pm 1.8 \\
& 26.0 \pm 1.4 \\
& 28.5 \pm 1.3
\end{aligned}
$$

$\begin{array}{rll}8 & 30.7 \pm 1.8 & 180.7 \pm 3.1 \\ 7 & 26.0 \pm 1.4 & 178.4 \pm 2.7 \\ 15 & 28.5 \pm 1.3 & 179.7 \pm 2.0\end{array}$

28

28

20

11

10

21.0

20.8

Height

(cm)

Weight

(kg)

Body Fat

(\%)

$\begin{array}{ll}87.7 \pm 2.7 & 12.4 \pm 1.2 \\ 80.5 \pm 2.3 & 11.7 \pm 1.9 \\ 84.4 \pm 2.0 & 12.0 \pm 1.1\end{array}$

$54.1 \pm 1.8$

$59.5 \pm 2.4$

$56.6 \pm 1.6$

$83.4 \pm 1.5 \quad 19.5 \pm 0.7$

$73.8 \pm 0.9 \quad 12.2 \pm 0.7$

$182.6 \pm 1.4$

$89.1 \pm 2.1$

$14.6 \pm 0.9$

$46.3 \pm 2.0$

$179.0 \pm 2.4$

$77.6 \pm 3.5$

$12.7 \pm 0.6$

$50.3 \pm 1.5$

$51.0 \pm 1.1$
$176.3 \pm 1.2$

$174.6 \pm 1.0$

$75.7 \pm 1.9$

$9.6 \pm 0.7$

$58.4 \pm 0.8$

$69.4 \pm 2.1$

$12.4 \pm 0.7$

$57.8 \pm 2.2$

$173.3 \pm 2.3$

$80.6 \pm 3.9$

$8.4 \pm 0.3$

$55.7 \pm 1.6$

$200.6 \pm 1.5$

$188.0 \pm 2.6$

$96.9 \pm 1.9$

$83.6 \pm 1.6$

$9.1 \pm 1.4$

$10.6 \pm 1.1$

$45.9 \pm 1.1$

$50.0 \pm 1.4$

$179.0 \pm 1.4$

$77.3 \pm 1.6$

$13.1 \pm 0.8$

$61.5 \pm 1.2$

$64.7 \pm 1.3$ marginally leaner than other professional soccer players studied by Williams et al (1976) and the Finnish ice hockey players (Rusko et al, 1978).

The aerobic capacity of the Rochester rugby players, with a mean $\mathrm{VO}_{2}$ max of $56.6 \mathrm{ml} . \mathrm{kg}^{-1} \mathrm{~min}^{-1}$, was superior to that of the other rugby players studied (Bell, 1980); Williams et al, 1973; Reid and Williams, 1974), similar to both groups of professional soccer players (Williams et al, 1973; Raven et al, 1976) and to Olympic wrestlers (Silva et al, 1982). It was not, however, as high as that of either of the two groups of ice hockey players (Maud, unpublished data, Rusko et al, 1978) where the respective means reported were 64.7 and $61.5 \mathrm{ml} . \mathrm{kg}^{-1}$ $\mathrm{min}^{-1}$, but was greater than that of both professional basketball forwards and guards, average 45.9 and 50.0 $\mathrm{ml} . \mathrm{kg}^{-1} \mathrm{~min}^{-1}$, studied by Parr et al (1978).

Data for comparison between other fitness parameters measured in this study and other rugby and intermittent sport studies is less extensive due either to a relative paucity of such data or to differences in measurement technique. Some comparisons are, however, possible.

The Rochester team mean scores can be compared 


\section{TABLE III}

Anaerobic power and anaerobic capacity of a rugby union team.

\begin{tabular}{|c|c|c|}
\hline Position & $\begin{array}{c}\text { Anaerobic* } \\
\text { Power Output } \\
\left.\text { (m.kg. } .^{-1}\right) \\
\left(\times 1 \sigma^{2} \mathrm{kw}\right)\end{array}$ & $\begin{array}{c}\text { Anaerobic* * } \\
\text { Capacity } \\
\text { m.kp/40 s. } \\
\left(x 10^{2} \mathrm{~kJ}\right)\end{array}$ \\
\hline \multicolumn{3}{|l|}{ Forwards } \\
\hline Prop & 145.5 & 2232 \\
\hline Prop & 151.5 & 2574 \\
\hline Hooker & 104.7 & 2142 \\
\hline Lock & 142.4 & 2214 \\
\hline Lock & 133.0 & 2286 \\
\hline Flanker & 140.8 & 2124 \\
\hline Flanker & 128.7 & 2232 \\
\hline No. 8 & 150.5 & 2250 \\
\hline $\begin{array}{l}\text { Forwards Mean } \pm \text { S.D. } \\
( \pm \text { S.E.) }\end{array}$ & $\begin{array}{c}137.1 \pm 15.3 \\
(5.4)\end{array}$ & $\begin{array}{c}2257 \pm 139 \\
(49)\end{array}$ \\
\hline \multicolumn{3}{|l|}{ Backs } \\
\hline Scrum Half & 111.6 & 2124 \\
\hline Fly Half & 115.0 & 2196 \\
\hline Centre & 115.7 & 2250 \\
\hline Centre & 142.7 & 2358 \\
\hline Wing & 131.8 & 2070 \\
\hline Wing & 141.4 & 2322 \\
\hline Full Back & 131.3 & 2326 \\
\hline $\begin{array}{l}\text { Backs Mean } \pm \text { S.D. } \\
( \pm \text { S.E.) }\end{array}$ & $\begin{array}{c}127.1 \pm 13.0 \\
(4.9)\end{array}$ & $\begin{array}{c}2235 \pm 110 \\
(41)\end{array}$ \\
\hline $\begin{array}{l}\text { Total Team Mean } \pm \text { S.D. } \\
( \pm \text { S.E.) }\end{array}$ & $\begin{array}{c}132.4 \pm 14.7 \\
(3.8)\end{array}$ & $\begin{array}{c}2247 \pm 122 \\
(32)\end{array}$ \\
\hline
\end{tabular}

with the percentile scores derived by Howe (1981) from a study of Canadian rugby players where values for the vertical jump, the endurance sit-ups, and the bench press would place them in the 55th, 50th, and 25th percentiles respectively.

A limited comparison to other intermittent sports can also be made with regards to anaerobic power and anaerobic capacity. In the current study the $\mathbf{4 0}$ second anaerobic capacity test was found to average 2247 m.kp (22.5 kJ) for the rugby players which compares with a mean of 2592 m.kp for college basketball players (Maud and Dyer, 1978) and 2292 m.kp for college ice hockey players (Maud, 1982). Anaerobic power was determined by use of the Lewis equation (Fox and Mathews, 1974) where the two variables required for the calculation are vertical jump and body weight measurements. The Rochester rugby players had a mean score of $132.4 \mathrm{~m} . \mathrm{kg}^{-1} \mathrm{~s}^{-1}(1.32 \mathrm{kw})$ which compared favourably with 120.9 m.kg.s ${ }^{-1}(1.21 \mathrm{kw})$ for college ice hockey players (Maud, unpublished data). Utilisation of vertical jump alone as the power measurement, where the rugby players average jump was $50.6 \mathrm{~cm}$, allows comparison with college basketball players (Maud and Dyer, 1978), professional soccer players (Raven et al, 1978), and ice hockey players (Maud, unpublished data) where the respective mean values were 58.9, 52.8 and 48.7.

In any attempt to compare athletes from different sporting events it is important to consider the percentage contribution of the different energy systems utilised for a specific event and also for a specific playing position responsibility. Unfortunately it has not yet proven possible to determine these percentage contributions exactly. However, Fox and Mathews (1974) have attempted to estimate the contribution for some activities including basketball, ice hockey, soccer, and wrestling, and Morton (1978) has done likewise for rugby.

Tight five forwards in rugby are estimated to utilise $45 \%$ anaerobic energy sources and $55 \%$ aerobic sources with other positions more anaerobic in nature varying from $55 \%$ to $85 \%$ anaerobic and $15 \%$ to $45 \%$ aerobic. Basketball, ice hockey, and wrestling are suggested as utilising $80 \%$ to $90 \%$ anaerobic and $10 \%$ to $29 \%$ anaerobic/aerobic systems, and therefore it would be expected that because of their greater reliance on anaerobic metabolism these athletes would perform better in anaerobic and less well in aerobic tests than the rugby players. In some cases this was not the case, and it is interesting to note that both groups of ice hockey players were superior in aerobic performance when their sport is supposedly low in aerobic demands. Differences in training programmes could probably account for these discrepancies.

Soccer players are suggested to have energy demands more similar to rugby players with halfbacks, for example, estimated to utilise $60 \%$ anaerobic, $20 \%$ anaerobic/aerobic, and $20 \%$ aerobic sources. It is not, therefore, surprising to find that their aerobic capacities are similar to those of the rugby players.

If rugby, like other intermittent sports, is a sport where a large percentage of the energy source is anaerobic, then future studies of the physiological demands of the game need to include assessment of this factor. Although this relatively large percentage may be anaerobic in nature the limiting factor for continued exercise is aerobic metabolism during the recovery periods.

\section{SUMMARY}

This paper describes a variety of anthropometric and physiological variables that help to describe a USA amateur rugby union club team. Generally these players 
exhibited higher aerobic capacities and the forwards carried a lower percentage of body fat than other groups of rugby players studied, but the team tended to be weaker in upper body strength. Further, they appeared to compare favourably with other elite amateur and professional intermittent sports athletes.

\section{REFERENCES}

Annarino, A., 1976. Developmental Conditioning for Women and Men. C. V. Mosby, Saint Louis.

Bell, W., 1973 "Distribution of skinfolds and differences in body proportions in young adult rugby players". J.Sports Med.Phys. Fitness 13: 69-73.

Bell, W., 1973 "Anthropometry of the young adult college rugby player in Wales". Brit.J.Sports Med. 7: 298-299.

Bell, W., 1979 “Body composition of rugby union football players". Brit.J.Sports Med. 13: 19-23.

Bell, W., 1980 "Body composition and maximal aerobic power of rugby union forwards". J.Sports Med.Phys. Fitness 20: $447-451$.

Brozak, J., LeGrande, J., Anderson, T. and Keys, A., 1963 "Densiometric analysis of body composition: revision of some quantitative assumptions". Ann.NY Acad.Sci. 110: 113-140.

Consolazio, F., Johnson, R. and Pecora, L., 1963. Physiological Measurements of Metabolic Functions in Man. McGrawHill, New York.

Evans, E. G., 1969 "Fitness scores of Welsh youth rugby football players". Brit.J.Sports Med. 4: 60-62.

Evans, E. G., 1973 “Basic fitness testing of rugby football players". Brit.J.Sports Med. 7: 385-388.

Fox, E. and Mathews, D., 1974. Interval Training. Conditioning for Sports and General Fitness. Saunders, Philadelphia.

Hatakeyama, T., Higashiani, T., Koga, K., Meshizuka, T., Nakamura, M. and Tanaka, M., (Ed. Landry, F. and Orban, W.), 1976 "A comparative study on physical fitness between Canadian and Japanese rugby players over forty". (International Congress of Physical Activity Sciences, Quebec City, 1976). Exercise Physiology. Fitness and Performance Capacity Studies. Symposia Specialists, Inc., Miami.

Howe, B., 1980 "Team Canada's fitness program". Rugby, July 14: 30.

Howe, B., 1981 "Fitness testing and standards". Rugby, July 6: 32.

Jackson, A. and Pollock, M., 1978 "Generalised equations for predicting body density of men". Brit.J.Nutr. 40: 497-504.

Katch, V., Weltman, A., Martin, R. and Gray, L., 1977 "Optimal test characteristics for maximal anaerobic work on the bicycle ergometer". Res. Q.Am.Assoc. Health Phys.Educ. 48: 319-327.

Maud, P. and Dyer, G., 1978 "A comparison of physical fitness levels between the University of New Orleans and Tulane University basketball teams". Louisiana J.Health Phys.Educ. Rec. 41: 16-17.

McDonough, J., Kusumi, F. and Bruce, R., 1970 "Variations in maximal oxygen intake with physical activity in middleaged men". Circulation 46: 747-751.

Meyers, C., Golding, L. and Sinning, W., 1978. The Y's Way to Physical Fitness. Rodale Press, Emmaus, Pa.

Morton, A., 1978 "Applying physiological principles to rugby training". Sports Coach 2 (2): 4-9.

Parr, R., Wilmore, J., Hoover, R., Bachman, D. and Kerlan, R., 1978 "Professional basketball players: Athletic profiles". Physician Sportsmed. 6: 77-84. 
Raven, P., Gettman, L., Pollack, M. and Cooper, K., 1976 "A physiological evaluation of professional soccer players". Brit.J.Sports Med. 10: 209-216.

Reid, R. and Williams, C., 1974 "A concept of fitness and its measurement in relation to rugby union football". Brit.J. Sports Med. 8: 96-99.

Rusko, H., Havu, M. and Karvinen, E., 1978 "Aerobic performance capacity in athletes". Europ.J.Appl.Physiol. 38: 151-159.

Silva, J., Shultz, B., Haslam, R., Martin, T. and Murray, D., 1983 "Psychophysiological characteristics of the 1980 United States Olympic freestyle and Greco Roman wrestling candidates". In press.

Williams, C., Reid, R. and Coutts, R., 1973 "Observations on the aerobic power of university rugby players and professional soccer players". Brit.J.Sports Med. 7: 390-391.

Wilmore, J., 1977. Athletic Training and Physical Fitness. Principles and Practices of the Conditioning Process. Saunders, Philadelphia.

Wilmore, J., 1979 "The application of science to sport: physiological profiles of male and female athletes". Can.J. Appl.Spt.Sci. 4: 103-115.

\section{BOOK REVIEW}

Title: $\quad$ SKELETAL INJURY IN THE CHILD

Author: John A. Ogden

Publisher: Lea and Febiger, Philadelphia Price: $\$ 115.00 \quad £ 78.20$

Children's fractures are common and the number of text books specifically dealing with such injuries few in number.

This is a comprehensive book which deals with the subject in great detail and in so doing consists of 650 pages. Each chapter ends with a comprehensive list of references.

The book is split into two sections. The first section deals with the general principles of bone development, bone injury and bone repair. It also deals with the general principles of radiology of bone injury in children. The second section deals with specific injuries on an anatomical basis.

Throughout the text the standard of radiographic examples is excellent as are the line drawings. The text is dealt with in the greatest detail with great accuracy. When dealing with specific injuries each chapter is broken down into the anatomy of the area under discussion followed by a detailed discussion of each particular injury. Each particular injury is discussed from the point of view of aetiology of the injury, classification of the injury, pathomechanics, diagnosis, treatment and complications of that injury making clear reading.

In summary an excellent and very detailed book. It is a must for libraries as a reference book but in view of its price and very detailed approach, will only appeal to a few orthopaedic consultants for personal use.

M. J. Allen, FRCS 